\title{
Results of a New Technique for Implantation of Nonrestrictive Glaucoma Devices
}

\author{
${ }^{1}$ Gabriel Enrique Ortiz Arismendi,Cristina del Pilar Peña Valderrama, ${ }^{3}$ Oscar Albis-Donado
}

\begin{abstract}
Objective: To describe and present results of an original technique for nonvalved glaucoma implants.
\end{abstract}

Patients and methods: Thirty-five eyes of 34 patients with aggressive and/or advanced glaucomas of different causes were included. A Baerveldt implant was used in all cases, using an absorbable ligature that had been titrated to allow flow from day 1 , but avoiding hypotony. Intraocular pressure (IOP) during the first 8 weeks, final IOP, visual acuity and complications were analyzed.

Results: Mean preoperative IOP was $42.8 \mathrm{~mm} \mathrm{Hg}$ (range: 24-64 $\mathrm{mm} \mathrm{Hg}$ ). IOP was 14.4, 17.2, 18.6, 19 and $16.4 \mathrm{~mm} \mathrm{Hg}$ during the 1, 2, 4, 6 and 8 postoperative weeks. Mean final IOP was $13.8 \pm 4.25 \mathrm{~mm} \mathrm{Hg}$, a $67.8 \%$ reduction, after a mean follow-up time of 13 months (range: 8-29 months). Twentynine eyes $(82.9 \%)$ had complete success, two had qualified success $(5.7 \%)$ and four were failures $(11.4 \%)$. Choroidal detachments and transient tube obstructions were the most frequent complications.

Conclusion: Titrated ligature of Baerveldt tubes was effective for controlling IOP during both the early and late postoperative phases in eyes with severe glaucomas.

Keywords: Glaucoma surgery, Glaucoma implants, Titrated ligature.

How to cite this article: Arismendi GEO, delPilarPeña Valderrama C, Albis-Donado O. Results of a New Technique for Implantation of Nonrestrictive Glaucoma Devices. J Current Glau Prac 2013;7(3):130-135

Source of support: Preliminary results presented at the XXXI National Colombian Meeting of Ophthalmology Cartagena 2004, and published at the Revista Sociedad Colombiana de Oftalmologia 2008 41:1 507-517.

No funding or support was received for financing any part of the present study.

Conflict of interest: None declared

\section{INTRODUCTION}

Glaucoma implants are a valuable alternative for controlling intraocular pressure (IOP) in difficult to treat glaucomas that have been in use for the past 30 years. All implants share some common features, although design, materials and size differ. In all a tube is inserted into the anterior chamber that is connected to a main body or plate, located at or behind the equator, around which a fibrous capsule that regulates aqueous outflow is formed. Implants may have restrictive flow (e.g. Ahmed or Krupin) or unrestrictive (e.g. Molteno and Baerveldt). ${ }^{1}$

Implants with restrictive flow are designed to permit a more controlled flow from the beginning, while the tube must be occluded fully or partially during the first postoperative days in unrestricted implants to avoid severe hypotony. Occluding the tube will raise IOP until the ligature is removed or reabsorbed, an event that is usually planned for a time when sufficient fibrosis is formed around the implant, usually after 3 to 6 weeks. During this hypertensive period, eyes with advanced glaucomas or those with very high initial IOP might suffer additional devastating damage. Making venting slits anterior to the ligature, or using a suture inside the tube to permit some limited flow are established techniques that tend to have unpredictable results. ${ }^{2,3}$

After years of using Baerveldt implants we have devised the 'Ortiz' partial titrated ligature' technique to lower IOP from the first postoperative day with limited flow that lasts until the implant begins functioning fully.

\section{PATIENTS AND METHODS}

We report a case series of patients with difficult to control glaucomas, in whom a Baerveldt implant with partial titrated ligature was performed. Eyes in immediate need of an implant, with very high IOP on maximum tolerated therapy and/or advanced glaucoma damage were included. We excluded patients unable to comply with visits and those with less than 6 months of follow-up.

A signed informed consent was obtained from each patient after explaining the nature of the study and of the procedure. Our hospital's surgery investigation department and the ethics committee of the faculty of medicine of the Universidad Nacional de Colombia approved the protocol. Data was collected in a specially designed form that registered age, sex, race, diagnosis, date of the surgery, type of procedure, implant location and tube location, initial and final visual acuity, complications, additional procedures needed and initial IOP, plus IOP at day 1, weeks 1, 2, 4, 6 and 8th, and last recorded IOP.

Complete success was defined as an IOP above 5 and under 22 , with an IOP reduction of $30 \%$ or better without glaucoma medications, and qualified success if they needed glaucoma medications to reach this goal. Eyes with failure had IOP fewer than 6 , above 21 , less than $30 \%$ reduction, loss of light perception or phthisis bulbi. Reinterventions such as anterior tube revisions, YAG laser to unocclude the tube, or repair of an exposed tube were not considered failures as long as other criteria were still met. 


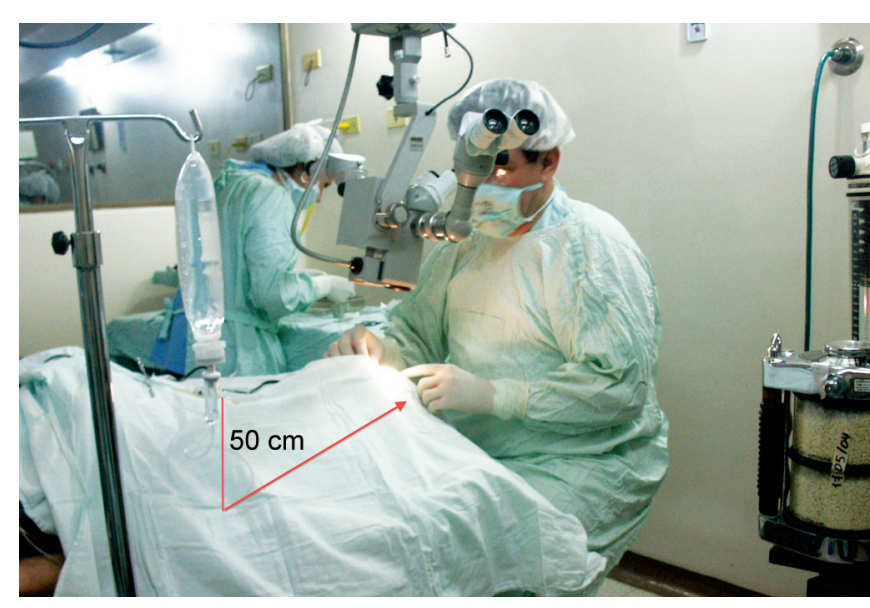

Fig. 1: The height of the irrigation bottle was $50 \mathrm{~cm}$ above the leve of the eye that needed to be operated, a column that corresponds to approximately $30 \mathrm{~mm} \mathrm{Hg}$ for doing the ligature titration

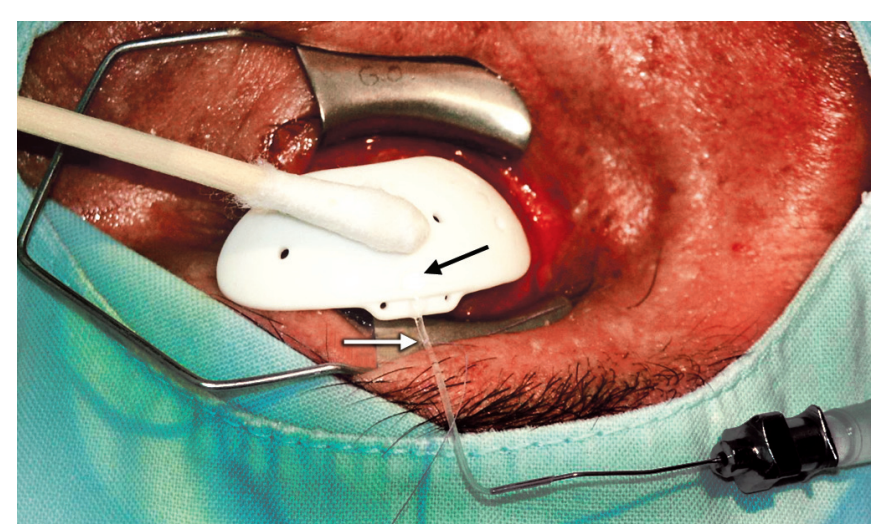

Fig. 2: The tubing connects the irrigation bottle to the tube of the implant via a $26 \mathrm{G}$ cannula and permeability is checked. The tube is ligated with an absorbable suture (white arrow) and the tension is adjusted until a very slow flow is achieved before the knot is secured (dark arrow)

\section{SURGICAL PROCEDURE}

The tube of the implant was connected through a $26 \mathrm{G}$ cannula to a BSS bag placed $50 \mathrm{~cm}$ above the head of the patient. Every $15 \mathrm{~cm}$ of height above the eye represents about $10 \mathrm{~mm} \mathrm{Hg}$, so any flow that occurred at this level would mean that pressure would be less than $30 \mathrm{~mm} \mathrm{Hg}$ (Fig. 1). Once the tube was tested for permeability the tube was ligated with an absorbable suture (7-0 or 8-0 polyglactin, Vicry ${ }^{\circledR}$ Ethicon Inc.) titrating for a slow, continuous flow of BSS, similar to checking the flow of a trabeculectomy (Fig. 2). Once the desired flow was obtained the suture was locked in place with 5 knots. Then the implant was fixed in place in the conventional manner, in the superotemporal quadrant, using a long-needle tract with a $23 \mathrm{G}$ needle bent as a $\mathrm{Z}$ without a patch (Dr Felix Gil's Technique). ${ }^{4}$

\section{Postoperative Regimen}

Every patient was examined on the first or second day, and at the end of weeks 1, 2, 4, 6 and 8 as per protocol, then every
2 to 3 months depending on IOP behavior or complications behavior. A topical antibiotic was used during the first week and prednisolone $1 \%$ every 2 to 4 hours during 8 to 10 weeks. Whenever, hypotony was present prednisolone was replaced with a nonsteroidal anti-inflammatory to promote a greater and faster scarring around the implant.

\section{RESULTS}

During the study period (January 2000 to December 2003) 53 eyes ( 19 were left eyes) of 51 patients received a Baerveldt implant, but 18 had to be excluded due to a short follow-up period.

We included 35 eyes of 34 patients, of which 22 were women; mean age was 59.9 years (range 22-73), including 30 mestizos, 3 Caucasian and 1 black. Demographic and surgical data for each case are included in Table 1. Most cases (25) received a Baerveldt $350 \mathrm{~mm}^{2}$ implant and the rest (10) a $425 \mathrm{~mm}^{2}$ implant. The tube was inserted into the anterior chamber in most eyes, 6 eyes additionally required an anterior or pars plana vitrectomy to avoid tube blockage.

Visual acuity improved in at least 1 line in 9 eyes, remained the same in 19 and worsened in 7. Initial visual acuity ranged from LP to 20/60 and final visual acuity from NLP to 20/40 (Table 2).

During follow-up the tube got blocked with vitreous in five cases, one could be treated with YAG laser vitreolysis, another also required medications and the other three additional surgical vitrectomy; one of these ultimately failed. One tube retracted out of the anterior chamber and needed to be relocated without loss of IOP control. Seven cases had transient hypotony with no choroidal detachments; only one of them had a mild shallow anterior chamber. Four additional cases had choroidal detachments, three of which were solved spontaneously; the other had to be drained. A patient who initially had light perception only had repeated tube extrusions and after finding calcified material inside the lumen, the tube was trimmed and removed from the anterior chamber. It was considered a failure and eventually needed cyclocryotherapy to further control IOP. In total 13 eyes needed additional procedures to either free the tube or relocate it in a better position (Table 3 ).

Mean initial IOP was $42.8 \mathrm{~mm} \mathrm{Hg}$ (range: 24-64), and it was $14.4,17.2,18.6,19$ and $16.4 \mathrm{~mm} \mathrm{Hg}$ during the 1, 2, 4, 6 and 8th postoperative weeks. Mean final IOP was 13.8 $\pm 4.25 \mathrm{~mm} \mathrm{Hg}$, a $67.8 \%$ reduction, after a mean follow-up time of 13 months (range: 8-29 months, Table 2, Graph 1).

Mean IOP for $425 \mathrm{~mm}^{2}$ implants was $14.7 \mathrm{~mm} \mathrm{Hg}$ and it was $13.5 \mathrm{~mm} \mathrm{Hg}$ for the $350 \mathrm{~mm}^{2}$ implant, a nonsignificant difference. Twenty-nine eyes $(82.9 \%)$ had complete success, two had qualified success $(5.7 \%)$ and four were failures 
Table 1: Patients, diagnosis and procedures

\begin{tabular}{|c|c|c|c|c|c|c|c|}
\hline No. & Age & Sex & Glaucoma diagnosis & Race & Tube location & Implant & Ligature material \\
\hline 1 & 54 & M & Pseudophakic AC IOL & MES & PC & Baerveldt 425 & 7-0 Vicryl \\
\hline 2 & 62 & M & Pseudophakic & MES & $A C$ & Baerveldt 350 & 7-0 Vicryl \\
\hline 3 & 75 & $\mathrm{~F}$ & PK & MES & $A C$ & Baerveldt 350 & 7-0 Vicryl \\
\hline 4 & 76 & $\mathrm{~F}$ & CACG & MES & $A C$ & Baerveldt 350 & 7-0 Vicryl \\
\hline 5 & 50 & M & PK & MES & $A C$ & Baerveldt 350 & 7-0 Vicryl \\
\hline 6 & 72 & $\mathrm{~F}$ & PK & MES & PC & Baerveldt 425 & 7-0 Vicryl \\
\hline 7 & 65 & $\mathrm{~F}$ & Uveitic & CAU & $A C$ & Baerveldt 350 & 7-0 Vicryl \\
\hline 8 & 65 & $\mathrm{~F}$ & Uveitic & CAU & $A C$ & Baerveldt 350 & 7-0 Vicryl \\
\hline 9 & 61 & $\mathrm{~F}$ & Pseudophakic & MES & VC & Baerveldt 350 & 7-0 Vicryl \\
\hline 10 & 70 & $\mathrm{~F}$ & Uveitic & MES & $A C$ & Baerveldt 350 & 7-0 Vicryl \\
\hline 11 & 69 & $\mathrm{~F}$ & PK & BLA & VC & Baerveldt 350 & 7-0 Vicryl \\
\hline 12 & 65 & $\mathrm{~F}$ & Aphakic & MES & VC & Baerveldt 350 & 8-0 Vicryl \\
\hline 13 & 49 & M & Pseudophakic & MES & $A C$ & Baerveldt 350 & 7-0 Vicryl \\
\hline 14 & 43 & $\mathrm{~F}$ & Pseudophakic & MES & $A C$ & Baerveldt 350 & 7-0 Vicryl \\
\hline 15 & 49 & M & Pseudophakic & MES & $\mathrm{AC}$ & Baerveldt 350 & 7-0 Vicryl \\
\hline 16 & 38 & M & Uveitic & CAU & $A C$ & Baerveldt 350 & 7-0 Vicryl \\
\hline 17 & 69 & $\mathrm{~F}$ & PK & MES & PC & Baerveldt 350 & 7-0 Vicryl \\
\hline 18 & 35 & M & NVG & MES & $A C$ & Baerveldt 350 & 7-0 Vicryl \\
\hline 19 & 65 & M & Pseudophakic & MES & $A C$ & Baerveldt 350 & 7-0 Vicryl \\
\hline 20 & 60 & $\mathrm{~F}$ & GPAA & BLA & $A C$ & Baerveldt 350 & 7-0 Vicryl \\
\hline 21 & 60 & M & PK & MES & $A C$ & Baerveldt 425 & 7-0 Vicryl \\
\hline 22 & 72 & $\mathrm{~F}$ & PK & MES & $A C$ & Baerveldt 425 & 8-0 Vicryl \\
\hline 23 & 64 & $\mathrm{~F}$ & Pseudophakic & MES & PC & Baerveldt 425 & 7-0 Vicryl \\
\hline 24 & 72 & $\mathrm{~F}$ & Pseudophakic & MES & VC & Baerveldt 350 & 7-0 Vicryl \\
\hline 25 & 37 & $\mathrm{~F}$ & PK & MES & PC & Baerveldt 350 & 7-0 Vicryl \\
\hline 26 & 67 & $\mathrm{~F}$ & PK & MES & $A C$ & Baerveldt 350 & 7-0 Vicryl \\
\hline 27 & 22 & $\mathrm{~F}$ & PK & MES & $A C$ & Baerveldt 425 & 7-0 Vicryl \\
\hline 28 & 65 & $\mathrm{~F}$ & PK & MES & PC & Baerveldt 425 & 7-0 Vicryl \\
\hline 29 & 38 & M & Post-traumatic & MES & $A C$ & Baerveldt 350 & 7-0 Vicryl \\
\hline 30 & 62 & M & PK & MES & $A C$ & Baerveldt 425 & 7-0 Vicryl \\
\hline 31 & 67 & $\mathrm{~F}$ & Pseudophakic & MES & $A C$ & Baerveldt 350 & 7-0 Vicryl \\
\hline 32 & 73 & $\mathrm{~F}$ & PK & MES & $A C$ & Baerveldt 425 & 7-0 Vicryl \\
\hline 33 & 64 & M & PK & MES & $A C$ & Baerveldt 350 & 7-0 Vicryl \\
\hline 34 & 70 & $\mathrm{~F}$ & PK & MES & PC & Baerveldt 350 & 7-0 Vicryl \\
\hline 35 & 73 & $\mathrm{~F}$ & Pseudophakic & MES & $A C$ & Baerveldt 425 & 7-0 Vicryl \\
\hline
\end{tabular}

AC: Anterior chamber; PC: Posterior chamber; VC: Vitreous cavity; MES: Mestizo; BLA: Black; CAU: Caucasian; IOL: Intraocular lens; PK: Penetrating keratoplasty; M: Male; F: Female; CACG: Chronic angle closure glaucoma; POAG: Primary open angle glaucoma; NVG: Neovascular glaucoma

(11.4\%, Table 2, Graph 2). Two failures were due to tube obstruction with vitreous, one to repeated tube extrusion and one neovascular glaucoma that went from hand movements to no light perception.

\section{DISCUSSION}

We found that modifying Baerveldt implant technique by using 'Ortiz' partial titrated ligature' was useful in our group of patients to lower IOP significantly during the immediate postoperative period, although not all eyes to normal levels.

Long-term results are also encouraging, since our success rate was $88.6 \%(84.9 \%$ cumulative success rate at 30 months by Kaplan-Meier), while maintaining a low complications rate, many transient and not needing many reinterventions. In fact, the seven cases of transient hypotony and the three cases of transient choroidal detachments are comparable to 
Results of a New Technique for Implantation of Nonrestrictive Glaucoma Devices

Table 2: IOP, visual acuity and final result

\begin{tabular}{|c|c|c|c|c|c|c|c|c|c|c|}
\hline \multirow[b]{2}{*}{ No. } & \multicolumn{2}{|c|}{ Visual acuity } & \multicolumn{7}{|c|}{ Intraocular pressure $(\mathrm{mm} \mathrm{Hg})$} & \multirow[b]{2}{*}{ Result } \\
\hline & Preoperative & Final & Pre & 1 day & 1 week & 2 weeks & 4 weeks & 6-8 weeks & Final & \\
\hline 1 & HM & HM & 48 & 24 & 30 & 34 & 38 & 26 & 16 & Success \\
\hline 2 & $20-60$ & $20-40$ & 41 & 18 & 19 & 17 & 18 & 12 & 17 & Success \\
\hline 3 & $\mathrm{HM}$ & $\mathrm{HM}$ & 32 & 7 & 17 & 23 & 22 & 13 & 13 & Success \\
\hline 4 & CF $1 \mathrm{M}$ & CF $1 \mathrm{M}$ & 38 & 9 & 17 & 24 & 3 & 8 & 8 & Success \\
\hline 5 & CF $50 \mathrm{~cm}$ & $\mathrm{HM}$ & 40 & 4 & 12 & 19 & 20 & 14 & 12 & Success \\
\hline 6 & $\mathrm{HM}$ & $\mathrm{HM}$ & 66 & 16 & 24 & 30 & 54 & 9 & 9 & Success \\
\hline 7 & $20 / 100$ & $20 / 70$ & 31 & 15 & 8 & 7 & 7 & 8 & 12 & Success \\
\hline 8 & CF & CF & 28 & 5 & 18 & 17 & 6 & 15 & 15 & Success \\
\hline 9 & $\mathrm{HM}$ & $\mathrm{HM}$ & 66 & 16 & 10 & 11 & 12 & 10 & 14 & Success \\
\hline 10 & CF $20 \mathrm{~cm}$ & CF $20 \mathrm{~cm}$ & 30 & 5 & 4 & 4 & 7 & 15 & 9 & Success \\
\hline 11 & LP & LP & 50 & 35 & 30 & 26 & 17 & 16 & 17 & Success \\
\hline 12 & $\mathrm{HM}$ & $\mathrm{HM}$ & 38 & 2 & 2 & 14 & 14 & 13 & 18 & Success \\
\hline 13 & CF A $1 M$ & CF $2 \mathrm{M}$ & 28 & 19 & 21 & 20 & 25 & 24 & 23 & Failure \\
\hline 14 & $\mathrm{HM}$ & $\mathrm{HM}$ & 39 & 9 & 12 & 14 & - & 8 & 13 & Success \\
\hline 15 & LPP & $\mathrm{HM}$ & 29 & 23 & 9 & 10 & 12 & 10 & 12 & Success \\
\hline 16 & $20 / 400$ & $20 / 400$ & 28 & 4 & 7 & 7 & 4 & 16 & 12 & Success \\
\hline 17 & $\mathrm{HM}$ & CF $2.5 \mathrm{M}$ & 52 & 28 & 24 & 28 & 29 & 22 & 20 & Relative success \\
\hline 18 & $\mathrm{HM}$ & NLP & 60 & 18 & 38 & 30 & 10 & 39 & 15 & Failure \\
\hline 19 & CF $50 \mathrm{~cm}$ & CF $50 \mathrm{~cm}$ & 44 & 22 & 23 & 20 & 22 & 15 & 17 & Success \\
\hline 20 & $20 / 60$ & $20 / 200$ & 24 & 22 & 24 & - & 28 & 10 & 14 & Success \\
\hline 21 & $\mathrm{HM}$ & CF $20 \mathrm{~cm}$ & 46 & 10 & 9 & 11 & 13 & 14 & 16 & Success \\
\hline 22 & $\mathrm{HM}$ & $\mathrm{HM}$ & 41 & 5 & 6 & 15 & 10 & 31 & 17 & Success \\
\hline 23 & $\mathrm{HM}$ & NLP & 60 & 16 & 30 & 22 & 30 & 19 & 24 & Failure \\
\hline 24 & $20 / 400$ & $20 / 400$ & 32 & 2 & 9 & 9 & 6 & 6 & 10 & Success \\
\hline 25 & LP & LP & 59 & 17 & 16 & - & 15 & 15 & 14 & Success \\
\hline 26 & $\mathrm{HM}$ & $\mathrm{HM}$ & 32 & 7 & 27 & 34 & 35 & 40 & 12 & Success \\
\hline 27 & CF $50 \mathrm{~cm}$ & CF $50 \mathrm{~cm}$ & 56 & 7 & 12 & 12 & 11 & 12 & 10 & Success \\
\hline 28 & $\mathrm{HM}$ & CF $1 \mathrm{M}$ & 46 & 20 & 26 & 22 & 46 & 22 & 8 & Success \\
\hline 29 & $20 / 100$ & $20 / 300$ & 40 & 21 & 25 & 24 & 11 & 12 & 11 & Success \\
\hline 30 & CF $3 \mathrm{M}$ & CF $3 \mathrm{M}$ & 39 & 17 & 16 & 14 & 18 & 12 & 16 & Success \\
\hline 31 & CF 2M & $20 / 800$ & 28 & 22 & 20 & 23 & 20 & 14 & 13 & Success \\
\hline 32 & CF $50 \mathrm{~cm}$ & CF 2M & 55 & 18 & 18 & 15 & 13 & 15 & 13 & Success \\
\hline 33 & $\mathrm{HM}$ & LP & 46 & 32 & 26 & 28 & 29 & 11 & 4 & Failure \\
\hline 34 & CF $20 \mathrm{~cm}$ & CF $20 \mathrm{~cm}$ & 42 & 8 & 7 & 16 & 59 & 29 & 12 & Success \\
\hline 35 & LPP & LPP & 64 & 2 & 16 & 15 & 12 & 20 & 18 & Relative success \\
\hline Mean & & & 42.8 & 14.429 & 17.235 & 18.63 & 19.6 & 16.42 & 13.82 & \\
\hline
\end{tabular}

NLP: No light perception; LP: Light perception; LPP: Light perception and projection; HM: Hand movements; CF: Counts fingers

\begin{tabular}{lcc}
\multicolumn{2}{c}{ Table 3: List of complications, some eyes had more than one } \\
\hline Complications & $n$ & Total (\%) \\
\hline Choroidal detachment & 4 & 11.4 \\
Tube occlusion & 4 & 11.4 \\
Tube exposure & 4 & 11.4 \\
Hyphema & 2 & 5.7 \\
Hypotony & 1 & 2.9 \\
Flat anterior chamber & 1 & 2.9 \\
Tube migration & 1 & 2.9 \\
Tube extrusion & 1 & 2.9 \\
Vitreous hemorrhage & 1 & 2.9 \\
Endothelial contact & 1 & 2.9 \\
Uveitis & 1 & 2.9 \\
\hline
\end{tabular}

the rates of the same complications reported for restrictive implants or even for unrestricted implants with full ligature after it has dissolved. ${ }^{5-7}$

Studies comparing restrictive and unrestricted implants have shown variable results. ${ }^{8,9}$ A previous comparison of Ahmed vs Baerveldt 350 that used similar success criteria as our study, found similar results between them, with

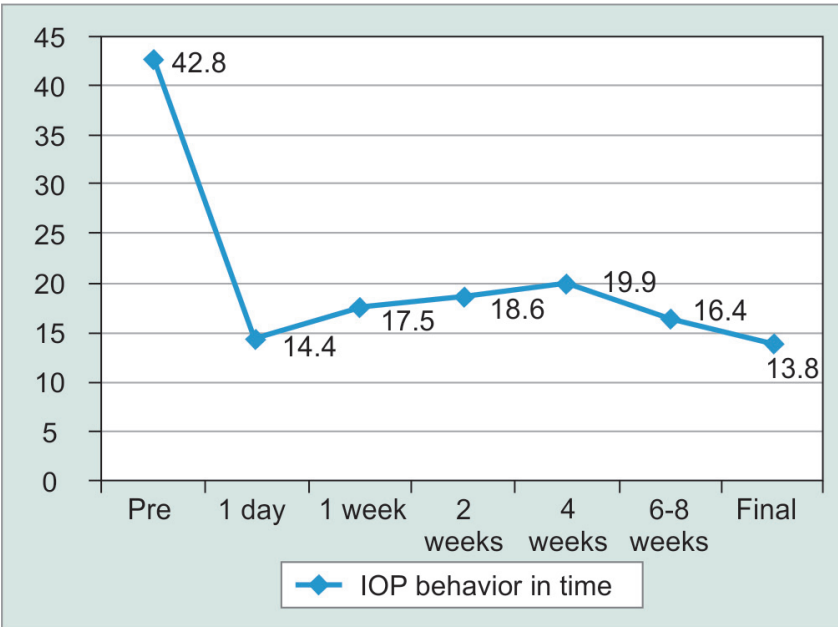

Graph 1: IOP behavior (in $\mathrm{mm} \mathrm{Hg}$ ) from the preoperative IOP, during the first 8 postoperative weeks and at last visit

complete success rates of 15.6 and $18.7 \%$, plus qualified success rates of 50 and $46.8 \%$ were not as good as in our final IOP of $12.1 \pm 5.3 \mathrm{~mm} \mathrm{Hg}$ and $13.6 \pm 5.6 \mathrm{~mm} \mathrm{Hg}$, but series. The rates of hypotony were $34.4 \%$ for the Ahmed 


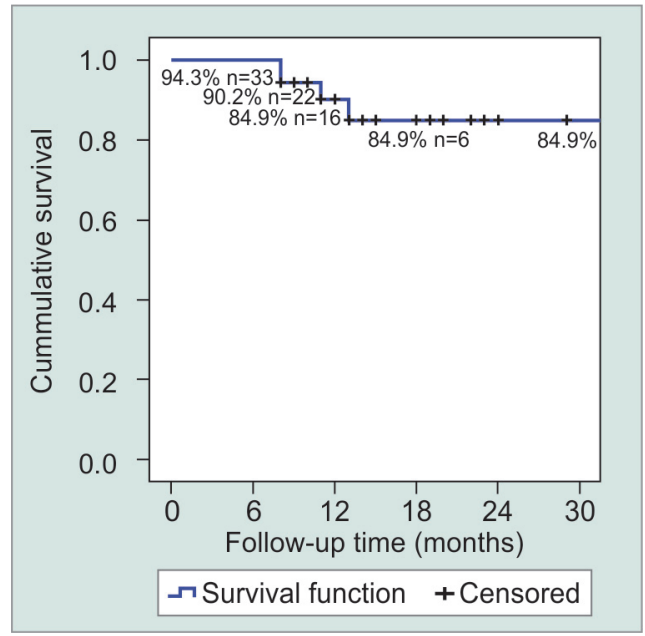

Graph 2: Kaplan-Meier survival plot, $\mathrm{n}$ indicates the number of remaining successful cases at each time-point

and $37.5 \%$ for the Baerveldt implants with venting slits in some eyes. ${ }^{10}$ We observed seven cases (20\%) of early hypotony with spontaneous resolution during the first 2 weeks in 6 , and at week 6 in the other.

Shallow anterior chamber was also present in one eye (2.8\%), a better rate than the typical 5 to $44 \%$ reported with several other implants. ${ }^{6-9}$

A hypertensive phase has been reported in up to $60 \%$ of Ahmed valves, beginning between weeks 2 and 6, requiring antiglaucoma medications and that will get better in a small percentage of cases after several months. ${ }^{11}$ A more recent study showed that the hypertensive phase lasted more than a year despite the use of mitomycin $\mathrm{C}$, in $40 \%$ of cases if a partial removal of Tenon's was performed and in $46 \%$ when it was not done. ${ }^{12}$ This prolonged hypertensive period was not present in our series, although a mild IOP elevation did occur in 4 eyes between months 2 and 3 that was spontaneously solved. Another 3 cases had early IOP elevation due to a too tight ligature or tube obstruction with either fibrin or vitreous.

Experimental studies in animals and humans have shown the formation of a fibrous capsule around the plate, which is responsible for primary resistance to aqueous outflow, and is made up of an inner acellular collagen band with spaces among its strands, an intermediate layer with greater organization and an external vascularized layer. ${ }^{14}$

There are three different Baerveldt models, with surface areas ranging from 250,350 and $425 \mathrm{~mm}^{2}$. The surface area for the Ahmed valve is $185 \mathrm{~mm}^{2}$ (and also of each additional plate), it is $184 \mathrm{~mm}^{2}$ for the Krupin and each Molteno plate has an area of $134 \mathrm{~mm}^{2}$. Several studies have found that a greater surface area is related with a better long-term aqueous outflow and a lower IOP, supporting a size of around $268 \mathrm{~mm}^{2}$ for a Molteno-type implant and $350 \mathrm{~mm}^{2}$ for Baerveldt. ${ }^{13-15}$ The roleof aqueous in the bleb during the initial postoperative period might decrease fibrosis and be related to better IOP in the long run, so having some flow of aqueous initially might be desirable ${ }^{14,16}$ This is an advantage of restricted implants and might explain why IOP reduction might be similar despite their smaller size and lower longterm outflow.

Among the disadvantages of restricted implants a higher risk of obstruction with detritus or inflammatory cells that might predispose them to a higher risk of a hypertensive phase.

An implant that is closer to the ideal should have a larger area for long-term IOP control, a good aqueous outflow that will indefinably keep those IOP levels without peaks, but with a low risk of hypotony despite having an effective IOP lowering in the early postoperative period.

Our method is in line with all these postulations, but requires experience and is affected by the subjectivity of the surgeon during flow titration, which makes it less reproducible. A more exact and standardized method to restrict early flow during the first weeks that eventually frees full flow is needed.

\section{SUMMARY}

The modified surgical technique that we used in this group of patients, allowed us to obtain a success rate that compares favorably with most published studies on glaucoma implants. Further studies to ascertain the reproducibility of the technique, the results and even the design of new implants aiming to improve long-term results and reduce complications are needed.

\section{REFERENCES}

1. Nguyen $\mathrm{QH}$. Avoiding and managing complications of glaucoma drainage implants. Curr Opin Ophthalm 2004 Apr;15(2):147150.

2. Rietveld E, van der Veen AJ. Postoperative pressure regulation in glaucoma shunt surgery: focal tube constriction is not the answer. J Glaucoma 2004 Jun;13(3):216-220.

3. Kansal S, Moster MR, Kim D, Schmidt CM Jr, Wilson RP, Katz LJ. Effectiveness of nonocclusive ligature and fenestration used in Baerveldt aqueous shunts for early postoperative intraocular pressure control. J Glaucoma 2002 Feb;11(1):65-70.

4. Albis-Donado, O. Atlas of glaucoma surgery. In: Shaarawy T, Mermoud A, editors. New Delhi, India: Jaypee Brothers Medical Publishers Pvt. Ltd; 2006. Chapter 6: the Ahmed Valve. p. 58-76.

5. Krupin T, Podos SM, Becker B, Newkirk JB. Valve implants in filtering surgery. Am J Ophthalmol 1976 Feb;81(2):232-235.

6. Krupin eye valve with disk for filtration surgery. The Krupin Eye Valve Filtering Surgery Study Group [editorial]. Ophthalmology 1994 Apr;101(4):651-658.

7. Coleman AL, Hill R, Wilson RM, Choplin N, Kotas-Neumann R, Tam M, Bacharach J, Panek WC. Initial clinical experience with the Ahmed Glaucoma Valve Implant. Am J Ophthalmol $1995 \mathrm{Jul} ; 120(1): 23-31$. 
8. Rosenberg LF, Krupin T. Implants in glaucoma surgery. In: Ritch R, Shields MB, Krupin T, editors. The glaucomas. 2nd ed. St. Louis: CV Mosby; 1996. p 1783-1807.

9. Taglia DP, Perkins TW, Gangnon R, Heatley GA, Kaufman PL. Comparison of the Ahmed Glaucoma Valve, the Krupin Eye Valve with Disk, and the double-plate Molteno implant. J Glaucoma 2002 Aug;11(4):347-353.

10. Syed HM, Law SK, Nam SH, Li G, Caprioli J, Coleman A. Baerveldt-350 implant versus Ahmed valve for refractory glaucoma: a case-controlled comparison. J Glaucoma 2004 Feb;13(1):38-45.

11. Nouri-Mahdavi K, Caprioli J. Evaluation of the hypertensive phase after insertion of the Ahmed Glaucoma Valve. Am J Ophthalmol 2003 Dec;136(6):1001-1008.

12. Susanna R Jr; Latin American Glaucoma Society (SLAG) Investigators. Partial Tenon's capsule resection with adjunctive mitomycin $\mathrm{C}$ in Ahmed glaucoma valve implant surgery. Br J Ophthalmol 2003 Aug;87(8):994-998.

13. Prata JA Jr, Santos RC, Labree L, Minckler DS. Surface area of glaucoma implants and perfusion flow rates in rabbit eyes. $\mathrm{J}$ Glaucoma 1995 Aug;4(4):274-280.

14. Wilcox MJ, Minckler DS, Ogden TE. Pathophysiology of artificial aqueous drainage in primate eyes with molteno implants. J Glaucoma 1994 Summer;3(2):140-151.

15. Heuer DK, Lloyd MA, Abrams DA, Baerveldt G, Minckler DS, Lee MB, Martone JF. Which is better? One or two? A randomized clinical trial of single-plate versus double-plate Molteno implantation for glaucomas in aphakia and pseudophakia. Ophthalmology 1992 Oct;99(10):1512-1519.

16. Francis BA, Cortes A, Chen J, Alvarado JA. Characteristics of glaucoma drainage implants during dynamic and steady-state flow conditions. Ophthalmology 1998 Sep;105(9):1708-1714

${ }^{1}$ Associate Professor and Chief of Glaucoma Section

${ }^{2}$ Assistant Professor, ${ }^{3}$ Professor

${ }^{1}$ Chief of Glaucoma Section, Ophthalmology Unit Faculty of Medicine, Universidad Nacional de Colombia, Clinica de Ojas Bogota, DC

${ }^{2}$ Ophthalmology Unit, Faculty of Medicine Universidad Nacional de Colombia, Bogotá, DC, Colombia

${ }^{3}$ Department of Ophthalmology, Association Para Evitar la Ceguera en Mexico, Mexico City, Mexico

Corresponding Author: Gabriel Enrique Ortiz Arismendi Associate Professor, Chief of Glaucoma Section, Ophthalmology Unit Faculty of Medicine, Universidad Nacional de Colombia Clinica de, Ojos, Calle 119A 57-35 (708) Bogotá DC, Colombia Phone: (+571) 6951786, (+571) 3014304194, e-mail: geortiza@ unal.edu.co 